\title{
FAMILIAL CALCIFICATION OF THE BASAL GANGLIA WITH RESPONSE TO PARATHORMONE
}

\author{
BY \\ W. B. MATTHEWS \\ From the Derbyshire Royal Infirmary
}

Massive symmetrical calcification of the basal ganglia and dentate nuclei is now a well recognized radiological finding and great emphasis has been laid on its association with hypoparathyroidism (Löwenthal, 1948). While such an association is undeniable the connexion between the two phenomena is ill understood and cannot at present be accepted as invariable. It is the purpose of this paper to describe a family in which certain members were afflicted in middle life by a progressive neurological disorder accompanied by calcification of the basal ganglia. No clinical or chemical evidence of hypoparathyroidism was present but, in the member investigated in detail, an abnormal response to parathyroid hormone was observed.

\section{Family History}

The family (Fig. 1) consisted of seven daughters born to parents who were reputed to be second cousins. A search of the parish registers of the small village where the family originated showed that in-breeding was common in the early nineteenth century but failed to establish the exact relationship of the parents. The father died aged 78, following prostatectomy, and the mother died aged 80 of unknown causes, neither having suffered from any neurological disorder.

I.1, the eldest daughter, committed suicide at the age of 25 .

I.2 was examined and radiographed at the age of 67 and found to be normal.

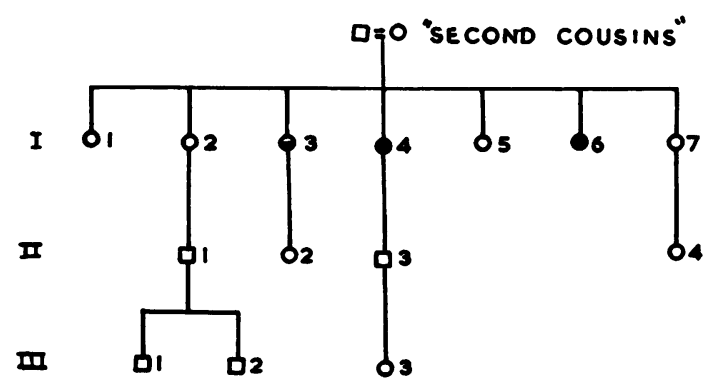

FIG. 1.-Pedigree of the family.
I. 3 had attended hospital at the age of $\mathbf{4 5}$ complaining of difficulty in walking but no diagnosis was made and, as far as is known, she was never radiographed. For 12 years before her death at the age of 54 her disease slowly progressed so that eventually she was bedridden. For the last few years of her life her speech had been slurred and she was incontinent of urine. According to her daughter she had never suffered from fits or from symptoms suggestive of tetany.

I.4 was admitted to the Derbyshire Royal Infirmary at the age of 61 . She said that for the past two years she hado experienced increasing difficulty in walking so that she्, could no longer leave the house. For the past year hef $N$ speech had been slurred and she was occasionally in $\vec{D}$ 음 continent of urine. She had no complaints about he arms but experienced much pain and stiffness in the back and legs.

She denied any serious illness in the past and, i⿺辶卬 particular, had never had any fits or symptoms resembling tetany and her thyroid had not been removed.

On examination she was a well built woman with $\vec{a}$ height of $165 \mathrm{~cm}$. and a normally shaped face. There were no deformities of the hands and feet nor of the skin or nails. A mild degree of dementia was present as judged by simple tests of recall and calculation but she could hold a rational conversation. Emotional lability was evident. She walked without swinging her arms, taking short steps with her feet wide apart and, if unsupported, she would fall. She had a fixed, unwinking expression and slurred, monotonous speech. The optic fundi were normal and there were no cataracts. The pupils and ocular movements were normal and there was no nystagmus. Rapid movements of the tongue could not be performed but the palate moved normally and the jaw jerk was not obtained.

There was no weakness of the arms and no tremor at rest but slight cog-wheel rigidity. She had bilateral intention tremor and alternating movements were clumsily performed.

The abdominal reflexes were absent.

There was increased resistance to passive movement in the legs but no demonstrable weakness and no involuntary movements. The tendon reflexes were uniformly brisk without clonus and the plantar reflexes were flexor. There was no sensory loss.

Chvostek's and Trousseau's signs were negative. The blood pressure was $140 / 80 \mathrm{~mm} . \mathrm{Hg}$. and no 
abnormality was found in the chest or abdomen.

Radiographs of the skull showed massive symmetrical calcification of the basal ganglia and dentate nuclei (Figs. 2 and 3).

In the course of the next year her condition showed a slow decline so that even walking with the aid of the furniture became difficult and for most of the time she was confined to a chair.

I.5 died in infancy.

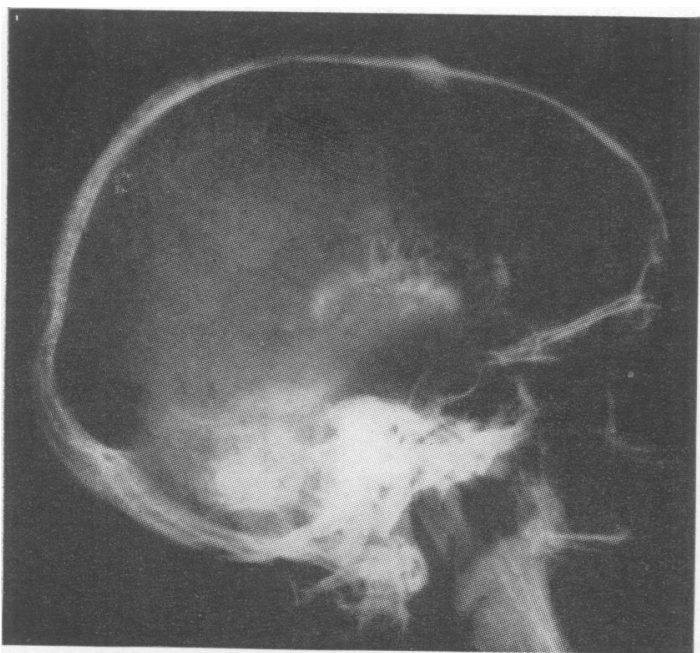

FIG. 2

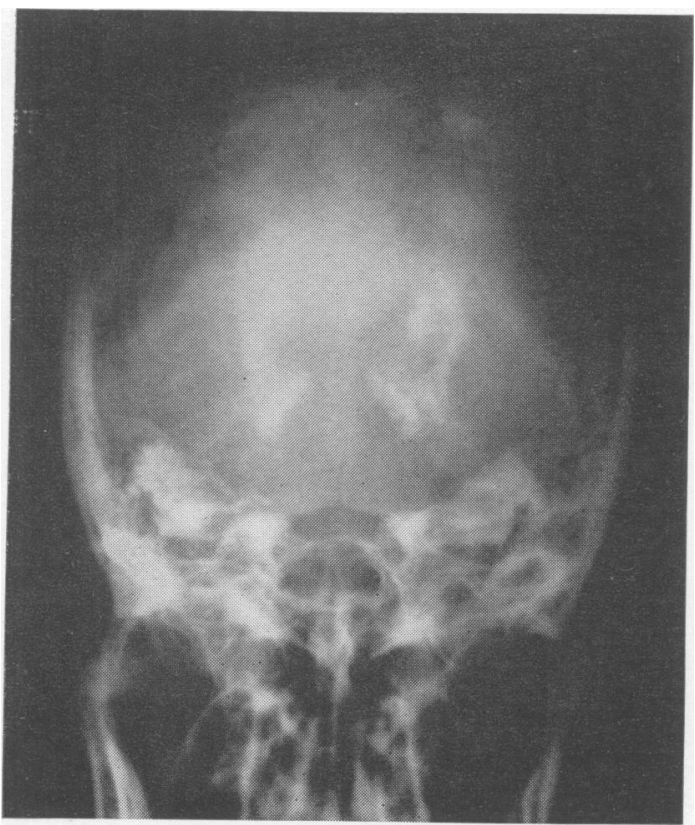

FIG. 3

Figs. 2 and 3.-Radiographs of the skull of Case 1.4 showing calcification.
I.6 was examined when aged 59. She had no complaints but it was possible to predict that she would show similar calcification as she resembled an early case of paralysis agitans with a fixed expression and a stooping stance. She did not swing her arms when walking but there was no tremor or ataxia. She had never suffered from fits or tetany and had no cataracts. Radiographs of the skull showed calcification perhaps even denser than in her sister (Figs. 4 and 5).

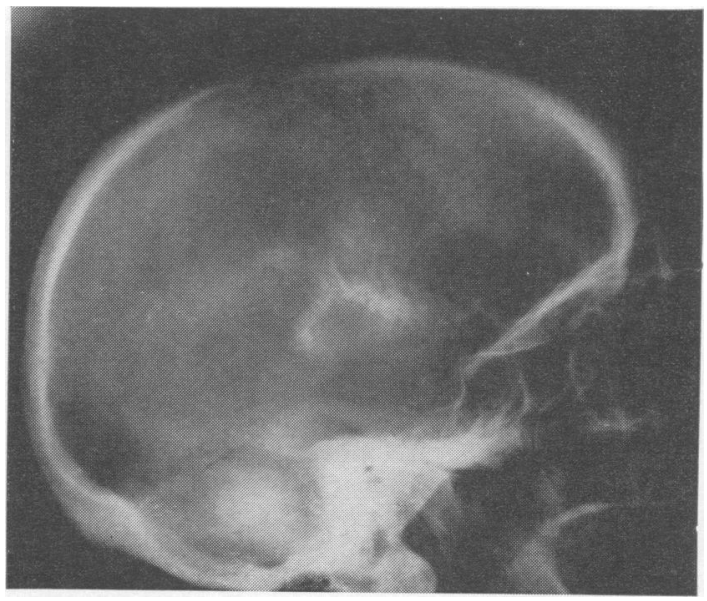

FIG. 4

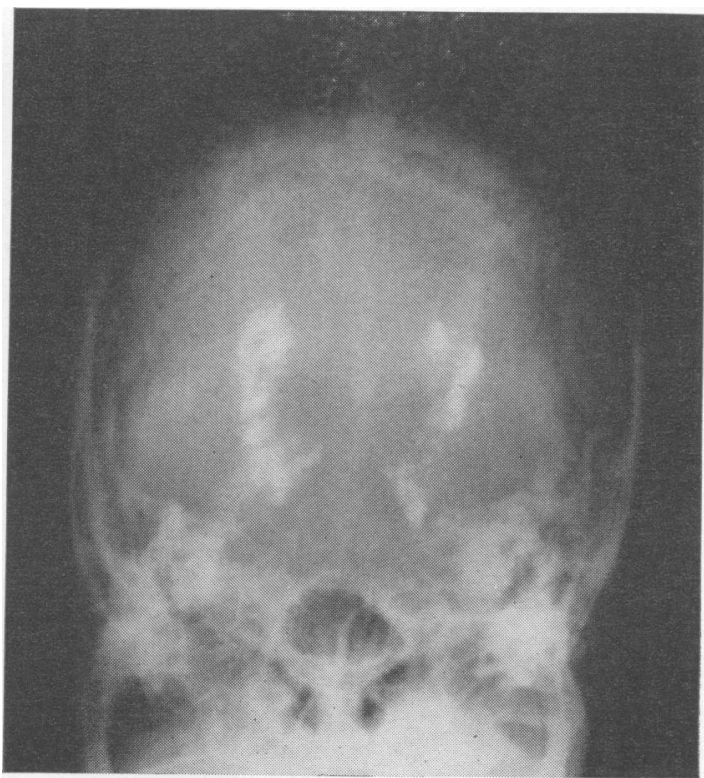

FIG. 5

Figs. 4 and 5.-Radiographs of the skull of Case I.6 showing similar calcification. 
I.7 was examined and radiographed at the age of 57 and found to be normal.

II. 1 was killed in the war.

II.2, aged 33, II.3, aged 28, and II.4, aged 23, were examined and radiographed with negative results.

III.1, 2, and 3 were small children stated to be normal but were not examined.

\section{Case $\mathbf{I . 4}$}

Case I.4 was investigated in detail, but the other surviving member of the family with neurological disease I.6, was not aware that she was affected and it was not thought permissible to draw attention to what appeared to be a progressive and incurable disease by admitting her to hospital.

The patient's urine contained no glucose or albumin. Dr. J. M. Walshe kindly examined the urine for aminoacids and reported a normal pattern of excretion.

The cerebrospinal fluid pressure was $100 \mathrm{~mm}$. and it contained $30 \mathrm{mg}$. of protein per $100 \mathrm{ml}$. and 1 white cell per c.mm. The Wassermann reaction was negative in blood and C.S.F.

The complement-fixation test for toxoplasmosis was negative.

The serum alkaline phophatase was $18 \mathrm{King}$-Armstrong units per $100 \mathrm{ml}$., the serum flocculation test was ++ . Total serum proteins were $6.5 \mathrm{~g}$. per $100 \mathrm{ml}$. (albumin $4.7 \mathrm{~g}$. and globulin $1.8 \mathrm{~g}$ ). There was no anaemia and the white cell count was normal.

The electroencephalograph was normal and consisted of low amplitude alpha with a little fast activity.

Calcium and phosphorus metabolism were investigated in greater detail. The serum calcium and phosphorus were estimated in all available members of the
TABLE I

SERUM CALCIUM, PHOSPHORUS, AND CHOLESTEROL LEVELS IN THE AFFECTED FAMILY

\begin{tabular}{c|cc:c}
\hline Patient & $\begin{array}{c}\text { Serum Calcium } \\
(\mathrm{mg} / 100 \mathrm{ml} .)\end{array}$ & $\begin{array}{c}\text { Serum Phosphorus } \\
(\mathrm{mg} . / 100 \mathrm{ml})\end{array}$ & $\begin{array}{c}\text { Cholesterol } \\
(\mathrm{mg} / 100 \mathrm{ml})\end{array}$ \\
\cline { 2 - 4 } I.2 & $9 \cdot 6$ & $2 \cdot 9$ & 261 \\
I.4 & $10 \cdot 0-11 \cdot 3$ & $2 \cdot 6-4 \cdot 3$ & 300 \\
I.6 & $10 \cdot 8$ & $4 \cdot 1$ & 238 \\
I.7 & 11.0 & $3 \cdot 6$ & 223 \\
II.2 & 10.4 & $3 \cdot 5$ & 215 \\
II.3 & 11.0 & 2.9 & 204 \\
II.4 & 10.2 & $3 \cdot 3$ & 219 \\
\hline
\end{tabular}

family and were all within normal limits. The serum cholesterol was also estimated as it was a little high in Case I.4 and had been raised in the cases reported by Bowman (1954). The results are shown in Table I.

Radiographs showed no subcutaneous calcification, normal bone density and no deformities of the hands or feet.

The C.S.F. calcium level was $5.0 \mathrm{mg}$. per $100 \mathrm{ml}$. and phosphorus $1.4 \mathrm{mg}$., which are normal figures.

On a normal diet the urinary phosphorus excretion ranged from 0.48 to $0.67 \mathrm{~g}$. per day and the calcium from 0.13 to $0.16 \mathrm{~g}$. A calcium balance was carried out on an intake of $1.0 \mathrm{~g}$. and also on a low intake of $0.2 \mathrm{~g}$. per day. On the former diet the output in the faeces was $2.24 \mathrm{~g}$. and in the urine $0.69 \mathrm{~g}$. over a four-day period, giving a positive balance of $0.25 \mathrm{~g}$. per day. On the low intake the faeces contained $0.29 \mathrm{~g}$. and the urine $0.45 \mathrm{~g}$. in four days, approximately equivalent to the intake. These results were interpreted as normal.

The effects of parathyroid hormone in producing an increased excretion of phosphorus in the urine and in $\varnothing 0$ elevating the serum calcium level were assessed. The용

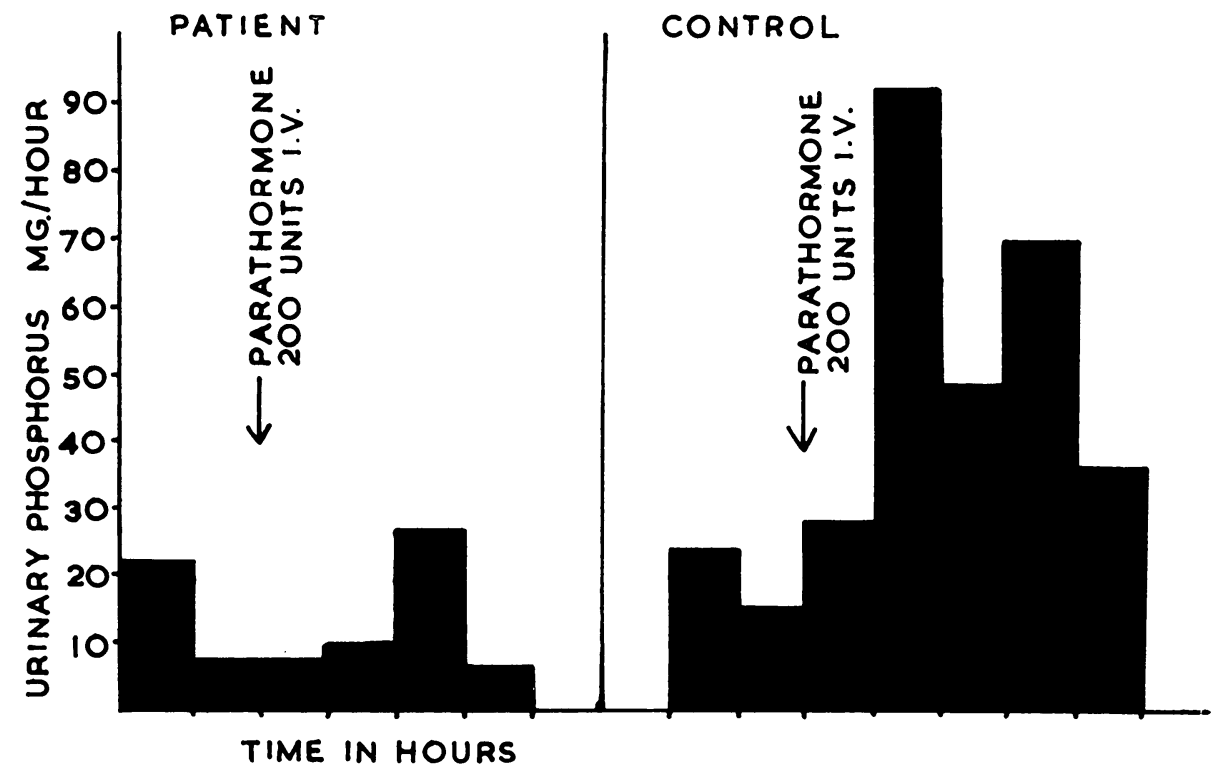

FIG. 6.-The effect of intravenous parathormone on phosphorus excretion in Case I.4 and one control subject. 


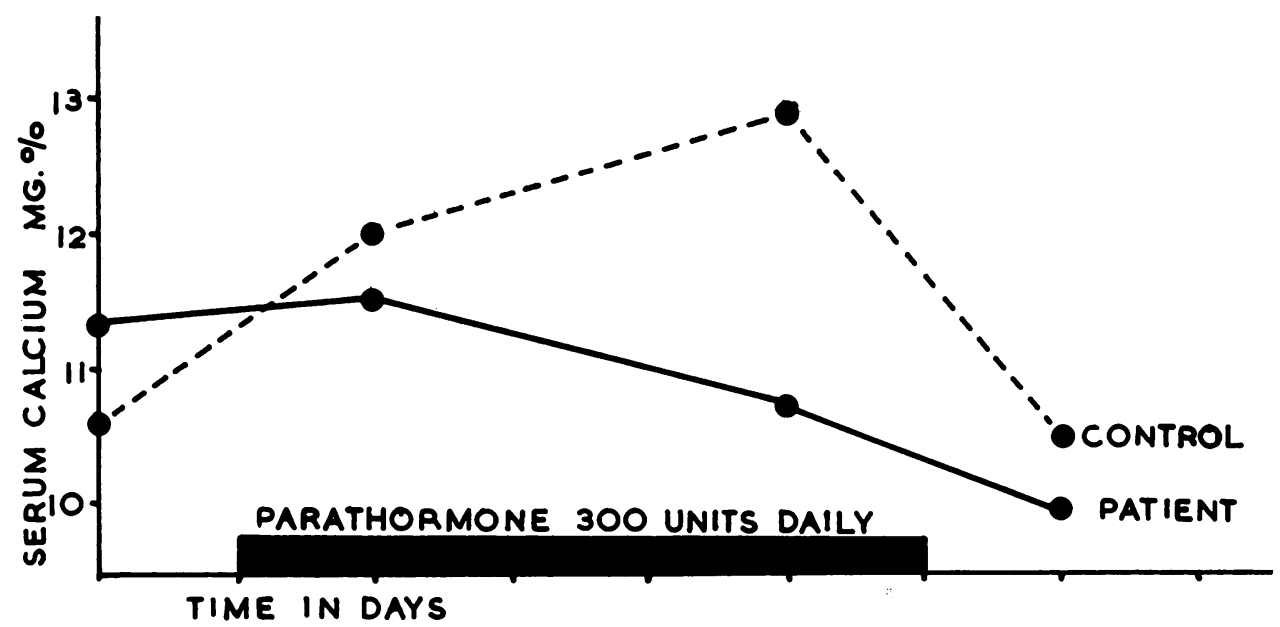

FIG. 7.-The effect of daily intramuscular injections of parathormone on the serum calcium in Case I.4 and one control subject. On the day preceding this test the patient had received a single intravenous injection of parathormone.

patient's urine was collected by catheter for two hours before and four hours after the intravenous injection of 200 U.S.P. units of parathormone. On the succeeding five days 300 U.S.P. units of parathormone were injected intramuscularly daily, serum calcium levels being estimated at intervals. The first procedure was repeated in one female control subject of approximately the same age and the second in a second control using the same batch of parathormone. The results are shown in Figs. 6 and 7 . It can be seen that no increase in phosphorus excretion and no rise in serum calcium occurred in the patient, in contrast to the results in the control subjects. No further supplies of this batch of parathormone were available.

\section{Discussion}

Minor degrees of calcification of the basal ganglia have been described in a great variety of conditions (Eaton, Camp, and Love, 1939) and it is difficult to assert that they have any pathological significance. The great majority of adequately investigated cases of massive calcification have been associated with obvious evidence of a generalized disorder of calcium and phosphorus metabolism due to failure of parathyroid function from different causes. The endocrine disorders described are those of idiopathic hypoparathyroidism and pseudo-hypoparathyroidism, and, as the causes of these conditions are unknown, it is arguable that the calcification and metabolic disorders might be due to some single unknown factor. The connexion must, however, be more direct as Siglin, Eaton, Camp, and Haines (1947) described massive calcification in a case of chronic post-operative tetany. The author has also investigated a woman whose thyroid had been removed 21 years before and who had suffered from recurrent tetany ever since. No neurological abnor- malities were present, apart from tetany if inadequately treated, but radiographs of the skull showed dense calcification of the basal ganglia and dentate nuclei. It must, therefore, be accepted that the endocrine disorder is the cause of the calcification.

Post-mortem evidence (Eaton and others, 1939; Eaton and Haines, 1939) shows clearly that it is not normal cerebral structures but excessive deposits of " hyaline" or " colloid" material of perivascular distribution that calcify. Albright (1939) has stated that the calcification is directly due to the raised plasma phosphorus leading to supersaturation of the plasma in respect of phosphorus and calcium, and the site of the calcification might be explicable by the concentration of phosphatase in the basal ganglia mentioned by Milne (1951). As far as is known, however, these factors would not be effective without the prior deposition of hyaline and it must be assumed that in some unknown manner the metabolic disorder of chronic hypoparathyroidism is also responsible for this deposition.

Many cases have been inadequately investigated but there remains a small group of cases in which, using the inexacting criteria of the absence of spontaneous or induced tetany and a normal serum calcium level, no evidence of hypoparathyroidism was obtained. The cases of Guillain, Bertrand, and Rouquès (1936) and of van Bogaert (1949) have not been included in this group, as although the serum calcium level was normal, tetany was present and it is not yet possible to accept without reserve the suggestion that the tetany was of central and not of metabolic origin. The cases that fulfil these criteria 
are those of Foley (1951), Fritzsche (1935), Bowman (1954), Eaton and others (1939, Cases 4 and 5), Sammet and Bucy (1951), and Rand, Olsen, and Courville (1943, Case 1). The present family also falls into this group, which then comprises 15 cases. Of this number, 11 were familial or hereditary, while in the much larger group of those with known hypoparathyroidism the only familial cases of cerebral calcification discovered are those of Vasiliu (1940) and Camp (1947).

This strong familial tendency increases the temptation to place these cases in a separate category of a specific hereditary disease but a study of the case reports shows that they form very unpromising material for a clinical syndrome. The patient described by Foley (1951) closely resembled those in the present family and a minor degree of calcification was present in her two daughters who had no symptoms. In this family, therefore, inheritance appears to have been dominant. The three siblings described by Fritzsche (1935) were born of consanguineous parents, suggestive of recessive inheritance, and developed symptoms in early childhood. The two brothers described by Bowman (1954) were infants, both of whom probably had a nephrotic syndrome and who died before the age of 3 . Sammet and Bucy's (1951) case was a man of 43 without symptoms. Eaton and others' (1939) Case 4 developed recurrent hemiplegia at the age of 31 and their Case 5 was a defective woman of 40 without abnormal neurological signs. Rand and others' Case 1 suffered from epilepsy and hypertension but had no abnormal neurological signs. The great diversity of the clinical state must make it unlikely that there is any single cause of the calcification in this group of patients without evidence of hypoparathyroidism.

The investigation of the propositus in the present family, however, suggests that defects of parathyroid function may exist without producing any disturbance of serum calcium or phosphorus levels, at least at the time of the investigation. The condition of pseudo-hypoparathyroidism was described by Albright, Burnett, Parson, and Sulkowitch (1941) as an example of failure of the target organs to respond to normally produced hormone. As far as is known the target organs of the parathyroid hormone are the bones and the renal tubules. Albright and his colleagues established the lack of response by the failure of injected hormone to produce an increased urinary excretion of phosphorus, using the Ellsworth-Howard test (Ellsworth and Howard, 1934). Certain physical stigmata frequently accompany this metabolic disorder: a round face, short stature, shortening of the metacarpal and metatarsal bones, and subcutaneous calcification. The condition is extremely rare and
MacGregor and Whitehead (1954) found only 27 cases in the literature that satisfied their criteria, 10 of which were known to have cerebral calcification. It must be emphasized that these patients have changes in the blood chemistry typical of hypoparathyroidism and suffer from chronic tetany. The concept of failure of target organ response has not passed unchallenged and certainly the EllsworthHoward test of response to parathyroid hormone is unreliable as it may be negative in normal subjects (MacGregor and Whitehead, 1954; Milne, 1951; Dent, 1953). This has been attributed to lack of this particular activity in the commercial gland extracts. The batch of parathormone used in this investigation was, however, shown to be active in producing an increase in phosphorus excretion in a normal control. The extract was also effective in raising the serum calcium level in a second control but produced no rise in the patient. This latter effect is probably due to the action of the hormone on bone (Milne, 1951), and failure of this response is considered more significant than the failure to increase phosphorus excretion (Dent, 1953; MacGregor and Whitehead, 1954).

This patient therefore showed two features of pseudo-hypoparathyroidism, namely, cerebral calci-ণ fication and a failure of response to parathyroid $\overparen{\odot}$ hormone, but without changes in blood chemistry or any of the physical stigmata commonly associated with the condition. The latter are known to occur independently of the chronic tetany and the condition of pseudo-pseudohypoparathyroidism has been described by Albright, Forbes, and Henneman (1952) and by Miles and Elrick (1955). This unwieldy name implies that the physical habitus and bone deformities, and in one case subcutaneous calcification, and in the other, cataract, may occur without changes in the blood chemistry or tetany. In the case of Albright et al. phosphorus excretion was not increased after parathormone but the extract was also inactive in a normal subject. In neither case was cerebral calcification present. That this condition bears some relationship to pseudohypoparathyroidism is shown by the family reported by Selye (1949) where mother and daughter showed the characteristic deformities but hypocalcaemia was present only in the daughter. If the tests can be accepted as showing lack of response to parathyroid hormone the patient reported here seems to represent a different fraction of the pseudo-hypoparathyroid syndrome. It is, of course, exceedingly difficult to reconcile a lack of response to injected hormone with an apparently normal response to the patient's own hormone as reflected in the absence of changes in blood chemistry. The answer may be a matter of the degree of abnormality. The 
family history is strongly suggestive of a recessively inherited metabolic disorder and the late age of onset of symptoms, presumably due to this disorder, may indicate that only a slight disturbance of function is present. Some response to parathyroid hormone must exist in order to maintain the serum calcium and phosphorus at normal levels but this might only be possible by a maximum response that could not be increased by injected hormone. Such an uneasy equilibrium would be unlikely to be perfectly maintained throughout life. It must not be forgotten that the lack of parathyroid function or of a normal response to the hormone appears to favour the excessive deposition of hyaline material in the basal ganglia, a change not obviously related to the known functions of the hormone nor necessarily related to measurable disturbances of blood chemistry.

\section{Summary}

A family is described in which three members developed a progressive neurological disorder in middle life, accompanied by massive symmetrical calcification of the basal ganglia and dentate nuclei in the two members who were examined.

No abnormality of blood chemistry was found in any member of the family but in the patient investigated in detail no response to parathyroid hormone could be obtained.
The possible relationships of this condition with those of pseudo-hypoparathyroidism and pseudopseudohypoparathyroidism are discussed.

The investigation of this family was greatly helped by the laboratory work of Mr. D. Watson, M.Sc., and Miss A. Matthews, B.Sc.

\section{REFERENCES}

Albright, F. (1939). In discussion of Eaton and Haines (1939). Burnett, C. H., Smith, P. H., and Parson, W. (1942). Endocrinology, 30, 922.

, Forbes, A. P., and Henneman, P. H. (1952). Trans. Ass. Amer. Phys., 65, 337 .

Bogaert, L., van, (1949). Mschr. Psychiat. Neurol., 118, 30.

Bowman, M. S. (1954). Amer. J. Path., 30, 87.

Camp, J. D. (1947). Radiology, 49, 568.

Dent, C. E. (1953). Proc. roy. Soc. Med., 46, 291.

Eaton, L. M., Camp, J. D., and Love, J. G. (1939). Arch. Neurol. Psychiat. (Chicago), 41, 921.

- and Haines, S. F. (1939). J. Amer. med. Ass., 113, 749.

Ellsworth, R., and Howard, J. E. (1934). Bull. Johns Hopk. Hosp., $55,296$.

Foley, J.'(195i). Journal of Neurology, Neurosurgery and Psychiatry, Fritzsche, R. (1935). Schweiz. Arch. Neurol., 35, 1.

Guillain, G., Bertrand, I., and Rouquès, L. (1936). Rev. neurol. (Paris), 65, 737.

Löwenthal, A. (1948). Acta neurol. psychiat. belge, 48, 613.

MacGregor, M. E., and Whitehead, T. P. (1954). Arch. Dis. Childh., $29,398$.

Miles, J., and Elrick, H. (1955). J. clin. Endocr., 15, 576.

Milne, M. D. (1951). Clin. Sci., 10, 471.

Rand, C. W., Olsen, C. W., and Courville, C. B. (1943). Bull. Los. Angeles neurol. Soc., $8,118$.

Sammet, J. F., and Bucy, P. C. (1951). Amer. J. Roentgenol., Selye, H. (1949). Textbook of Endocrinology, 2nd ed. Acta Endo-

Siglin, I. S., Eaton, L. M., Camp, J. D., and Haines, S. F. (1947).

Vasiliu, O. (1940). Wien. med. Wschr., 90, 153. 
an excellent account of existing knowledge, and can be recommended with every confidence to all concerned with the subject.

An Introduction to Electromyography. By Fritz Buchthal. (Pp. 43; 8 figures.) Copenhagen: Gyldendals Presseafdeling. 1957.

This simple introduction to electromyography is a useful guide to those who wish to take up the subject.

\section{Proceedings of the Second International Congress of Neuropathology, London, 1955}

At the request of the Organizing Committee of the Second International Congress of Neuropathology held in London, 1955, all reports, communications, and discussions presented to this congress have been published by the Excerpta Medica Foundation.

These Proceedings (edited by Dr. W. H. McMenemey) consist of three parts, Parts I and II containing 650 pages of text, and Part III containing 156 plates.

The Proceedings can be ordered from ExCERPTA Medica Foundation, 111 Kalverstraat, Amsterdam, The Netherlands, at the price of $£ 410$ s., fl. 50.-, or $\$ 12 \cdot 50$.

\section{International Association of Applied Psychology}

The XIIIth Congress will be held in Rome from April 9-14, 1958.

Those who wish to attend should apply to:

Segreteria del XIII Congresso, Internazionale di Psicologia Applicata,

Instituto Nazionale di Psicologia del C.N.R., Piazzale delle Scienze 7, RomA (Italia).

\section{Sherrington Memorial Lecture}

The first Sherrington Memorial Lecture, organized by The Royal Society of Medicine, will be delivered by Lord Adrian, O.M., M.D., F.R.S., in the Society's House at 8 p.m., on Wednesday, November 27, 1957.

The subject of the lecture is "The Analysis of the Nervous System ".

Admission will be by ticket only and applications for tickets may be made to the Assistant Secretary of the Society.

Correction.-The title of the paper by W. B. Mathews in the last issue of the Journal $(20,172)$ should read "Familial Calcification of the Basal Ganglia with Absence of Response to Parathormone."

\section{BOOKS RECEIVED}

(Review in a later issue is not precluded by notice here of books recently received.)

Practical Clinical Psychiatry, 8th ed. By Jack $\mathbf{R}$. Ewalt, Edward A. Strecker, and Franklin G. Ebaugh. (Pp. xiv + 457. 60s.) London: McGraw-Hill. 1957.

The Family in Psychotherapy. By C. F. Midelfort. (Pp. ix + 203. 49s.) London: McGraw-Hill. 1957.

Peripheral Nerve Regeneration: A Follow-up Study of 3,656 World War II Injuries. Edited by Barnes Woodhall and Gilbert W. Beebe. (Pp. xvii + 671; monograph, illustrated.) Washington, D.C.: Veterans Administration. 1956.

Der Suicid. By F. Dubitscher. (Pp. viii +224 ; 7 figures. DM 16.50.) Stuttgart: Georg Thieme. 1957.

Psychosomatic Medicine: A Clinical Study of Psychophysiologic Reactions, 3rd ed. By E. Weiss and O. S. English. (Pp. xix + 557; illustrated. 73s. 7d.) London and Philadelphia: W. B. Saunders. 1957.

Die Vaskulären Erkrankungen im Gebiet der Arteria vertebralis und Arteria basialis. By $\mathrm{H}$. Krayenbühl and G. Yasargil. (Pp. viii $+170 ; 125$ figures on 205 plates. DM 69.30.) Stuttgart: Georg Thieme. 1957.

Cerebral Lipidoses: A Symposium. Chairman: L. van Bogaert; Editor: J. N. Cumings; Assoc. Ed.: Lowenthal. (Pp. $\mathrm{x}+212$; illustrated. 42s.) Oxford: Blackwell. 1957.

New Research Techniques of Neuroanatomy. A Symposium sponsored by the National Multiple Sclerosis Society. Edited by William F. Winde; Foreword by Frederick L. Stone. (Pp. ix + 98; 25 figures. 36s.) Oxford: Blackwell; Springfield (Illinois): Charles C. Thomas. 1957.

Collection Testut. Precis de Neurologie, 6th edition entirely revised. By L. Rimbaud in collaboration with P. Passouant and $\mathrm{Cl}$. Gros. (Pp. 1186; 331 figures in black-and-white and colour. Fr.fr. 8,700.-.) Paris: G. Doin. 1957.

The Clinical Examination of Patients with Organic Cerebral Disease. By R. Klein and W. Mayer-Gross. (Pp. xiii + 96. 15s.) London: Cassell. 1957.

The Human Brain: From Primitive to Modern. By A. M. Lassek. (Pp. viii + 242. 36s.) Oxford: Blackwell; Springfield (Illinois): Charles C. Thomas. 1957.

Pneumoencephalography. By E. Graeme Robertson. (Pp. xxi + 482; 34 plates, 209 figures. £5 10s.) Oxford: Blackwell; Springfield (Illinois): Charles C. Thomas. 1957.

Mental Deficiency. By L. T. Hilliard and Brian $H$. Kirman. (Pp. xvi + 517; 90 figures. 60s.) London: J. \& A. Churchill. 1957. 